\title{
The Importance of Behavioral Economics during COVID-19
}

\author{
Javier Cifuentes-Faura \\ University of Murcia, Spain \\ javier.cifuentes@um.es
}

\begin{abstract}
Behavioral Economics seeks to understand the environments where decisions are made and to build proposals to optimize them. It offers the possibility to improve the design of public policies and, therefore, to enhance their results. The appearance of COVID-19 has caused thousands of deaths and millions of infected people around the world. This article describes the main behavioral biases that people exhibit during this pandemic. In order to curb the number of infections and stop the panic, it is essential to use Behavioral Economics tools, such as those proposed in this paper, to design messages that are simple and that motivate appropriate changes in human behavior. This work shows the importance of transmitting information correctly, of being aware of our own biases and that individual responsibility is fundamental to get out of this crisis.
\end{abstract}

Keywords: Behavioral Economics; COVID-19; human behavior; public policies.

\section{Introduction}

Man moves in an environment where there is asymmetric information, self-interest is not always sought and sometimes there are unusual preferences (Cárdenas et al., 2003). Daily observations show that man, does not always behave rationally. Economic agents are sometimes willing to sacrifice their own interest to satisfy different forms of social preferences (Fatás, 2004). Behavioral Economics is related to the fact that human beings seek to optimize their behavioral efficiency within the limits defined by internal and external constraints (Battmann \& Klumb, 1993; Michie, \& Johnston, 2012; Samson, 2014). It derives from reflections on the theory of rational choice by developing a systemic way of analyzing elements such as will power, selfinterest and rationality in decision making (Heshmat, 2011). Thus, with the use of economic reflections and analysis from psychological assumptions, it can be seen that the individual's decisions are loaded with errors of judgment that are programmed by our human condition (Kahneman, 2013). In this sense, the proposal of Behavioral Economics is to understand the environments where decisions are developed and to build proposals to optimize them. Although it follows the tradition of the free choice as a deliberative exercise.

It is sought that, with small pushes, or the so called "Nudge" (Thaler \& Sunstein, 2008), the individuals choose with help, but without restricting or limiting the options. The discussion on free choice is maintained under the theory of rational choice, seeking to promote citizens with the capacity to decide on what is appropriate for their lives. The human mind has restrictions to process information, since it does not have unlimited capacities of storage nor of analysis of the information (Kahneman, 2013). Many of the biases in human behavior result from immediate impressions, while others are part of a system already automatic, constituting themselves as habits, product of repetitions and associative learning (Duhigg, 2012). The pandemic caused by COVID-19 has meant that Behavioral Economics has taken on a very important role in stopping the pandemic. It is necessary to change people's behavior by changing the way possible options are presented at the time of making a decision. An example of this strategy during COVID-19 can be found in the markings on the floor that indicate the distance we should keep from the next person in line at a supermarket. Through the design of simple tools and messages, appropriate changes in human behavior should be promoted.

\section{Literature Review: Biases in Human Behavior}

Changing certain habits is very difficult among human beings, even with the necessary information. However, the whole population, with the help of government institutions, must try to change wrong behaviors during this pandemic. Effective hygiene and prevention measures should be promoted. Since one person infected with COVID-19 can infect many others, the challenge for government authorities is even greater. People rarely behave rationally and impartially when making decisions that affect the whole population and often use mental shortcuts that affect their perception of risk and reaction. For example, despite recommendations 
not to touch eyes, nose and mouth to prevent the spread of the corona virus, we touch our faces, on average, up to 23 times per hour (Kwok et al., 2015). In this regard, Haushofer and Metcalf (2020) have highlighted the importance of behavioral economics intervention.

In the effectiveness of promoting measures such as hand washing to reduce the number of infections. However, many times the population is not really aware of the need to carry out these practices. An epidemic such as COVID-19 creates an environment of excessive uncertainty under which human risk perception is driven by a strong sense of lack of control. The recent purchase of masks, disinfectant gels, and essential items along with the spread of false news, rumors, and misinformation encourages the emergence of two main biases:

- The retrospective bias. Once people know that an event has occurred, they delude themselves into thinking that they knew it was going to happen in the first place. With government decisions constantly evolving, bias in hindsight can make people perceive any new information about the fight against COVID-19 as inevitable. This may lead them to believe that policy makers should already have known where the situation was heading, making them question the credibility of the government's efforts.

- The availability bias. The probability of an outcome is judged by how quickly it comes to mind. If fearinducing images are continually presented and associated with COVID-19, people will not assess risk by the morbidity of the virus but by pre-existing beliefs, popularly called confirmation bias, and will judge the risks to be greater when they provoke stronger emotions.

In addition to these biases, it is also possible to identify the optimism bias and the illusion of control bias, which lead many people to engage in misconduct during the pandemic. The first bias is due to the fact that part of the population thinks that COVID-19 will not affect them, and they skip the restrictions, putting many vulnerable people around them in danger. The bias of the illusion of control will make us think that some concrete actions, such as hoarding toilet paper or making compulsive purchases in the supermarket, allow us to control the situation. Thus, for example, in order to carry out certain behaviors or actions there has to be a Motivation, a Capacity and a Stimulus (Fogg; 2009). The central idea of Fogg's model is based on the fact that if you want things to be done you must make them simple and easy for people. And it is in that quest for simplicity, speed and ease that the design of behavior is largely centered. For example, in the case of tasks, such as hand-washing, if the person is poorly motivated, the behavior will not occur.

\section{Methodology}

In this work, a review of the different behavioral biases and how they affect the human being during the situation caused by COVID-19 has been carried out, with the aim of reducing the impact of the pandemic, indicating solutions focused on Behavioral Economics to be applied by governments.

\section{Results and Discussion}

Government Measures to Reduce Bias during COVID-19: Behavioral Economics should encourage governments to eliminate the presence of behavioral biases in humans, so as to reduce the impact of the pandemic. The following are possible actions that should be taken by the government:

- Address availability bias and retrospective bias by communicating facts, action plans and the expected role of citizens in a clear and timely manner. The government must provide information on an ongoing basis and disprove fake news.

- Make it easier for citizens to find information about COVID-19 through official sources, and provide hotlines during the pandemic.

- Build a correct mental model for citizens, giving more publicity on government websites to the COVID-19 recovery cases than to the number of infected cases and victims, without downplaying the seriousness of the situation. 
- Showing videos of trusted public figures, who encourage self-care, express empathy and solidarity with patients, appreciate frontline health workers and destroy myths related to the virus.

- Continually demonstrate the need for precautionary measures such as hand washing and encouraging people to stay home.

- Make it mandatory to place soap and disinfectant dispensers by the entrance doors of offices, supermarkets, shopping centres and public buildings. These efforts towards effective risk communication by public authorities will help build the credibility of government measures, provide people with early guidance and allow uncertainty to be normalized. The communication strategy is key and it is best to report the seriousness of the situation with transparency and clarity, but without creating any kind of scaremongering. Behavioral Economics indicates that the response of citizens to the advice of the authorities on preventive measures is fundamental to get out of this crisis.

Sending simple and clear messages is essential to generate the necessary public reaction and reduce the health and economic costs of the epidemic. Therefore, we recommend during this crisis to follow these guideline:

- Inform in a clear and simple way, without causing panic or social alarm. The human being is not prepared to adapt psychologically to rapidly changing information and therefore needs to be aware that he or she will have to review information about the disease, its expansion and about the different treatments to combat it, so he or she must be prepared to assume changes.

- Unlike politicians, scientists and health professionals are among the most trusted professions among citizens. That is why it is important to centralize epidemiological information, and to some extent decisions, in health authorities, as they are the ones who may have the greatest epidemiological knowledge. The existence of emergency committees made up of scientific experts is necessary, not only to decide, but also to inform.

- Political confrontation should be avoided and the greatest possible coordination between institutions should be sought. To build trust, governing institutions should not take advantage of the situation to boast about good measures, nor should opposition criticize bad management.

- The media should transmit realistic information without taking advantage of the sensationalist vein that can lead them to attract attention. The focus should not be exclusively on the numbers of people affected and killed, but on what can and should be done to prevent the pandemic.

- Citizens must not create panic or spread misinformation, especially with the current degree of connectivity allowed by social networks.

Human beings are incapable of processing information in situations of stress and panic. Therefore, the messages conveyed must be simple and clear. Thus, massive purchases have been seen, which, although they can momentarily calm the human being, can collectively contribute to create shortages of health products or basic needs. Actions must be taken to avoid promoting misconduct among citizens that would further aggravate the situation.

Actions to Promote Desired Behavior among Citizens during the Pandemic: To date, we do not know, for example, many aspects of the origin and evolution of the epidemic, whether a vaccine will be available quickly or how our individual and group behavior affects the probability of contagion. In the face of uncertainty, the heterogeneity of individual attitudes to risk makes it difficult for us to coordinate the best preventive measures and eventually comply with them. An additional problem is our limited cognitive capacity to understand the probabilities of uncertain situations, which makes it difficult to inform in a clear and precise manner. One of the greatest difficulties in encouraging preventive behavior in the population.

In the face of an epidemic is that we pay the cost of prevention (increased hygiene, confinement to the home, etc.) now, while the possible benefits, which are also uncertain, will only be enjoyed in the future. The individual cost of taking preventive measures is higher for us individually than the benefit we derive from it. If each person does not have individual incentives to behave in a way that favors the collective, it will be more complex to stop the pandemic and will harm the whole population. It is therefore necessary to incorporate individual responsibility if we are to halt the spread of the disease. Therefore, from Behavioral Economics we 
must promote certain behaviors among the population from specific actions, such as those we have designed in Table 1.

Table 1: Tools Offered by Behavioral Design to Promote Certain Behaviors in the Population

Conduct to be Promoted

Use of protective masks

Hand wash

Avoiding crowds and purchases in supermarkets

Avoiding panic among the population

Confinement of young people

Do not touch your face Action to Encourage Desired Behavior

Incorporate testimonials from epimemiologists or physicians, as well as first patients in prevention campaigns.

At home: put up panels or posters at home that remind people of the need to wash their hands, along with graphic instructions on how to do so correctly. At work: place alcoholic sanitizing solution dispensers in strategic locations (at the entrance to the office, in the bathroom, etc.).

Restrict entries and exits, as well as the number of meals per person in order to avoid shortage

Testimony from popular and influential figures who recommend the use and monitoring of protective measures could be used

Promote public campaigns in the media about cases of young people with COVID-19. This helps to break down the belief among this population group that the disease attacks only the elderly (an idea favored by control and optimism biases).

You can wear a bracelet or a colored rubber band. This will not stop the transmission of the disease, but it will remind your brain to stop touching your eyes, nose, or mouth. An external object can act as a sensory clue to convert an unconscious habit into a conscious one. It's a way of asking your brain to pay attention to this strange phenomenon that happens with your hand.

Source: Own elaboration

Thus, an intervention based on Behavioral Economics would imply on the one hand the opportunity to provoke permanent changes that would translate into new habits with greater health benefits in the long term and on the other hand the reduction of the risk of overloading the health systems in the case of COVID19.

\section{Conclusion and Recommendations}

Without vaccination or preventive treatment against COVID-19 and the massive uncertainty associated with its risks, the corona virus has become a common threat to the entire population, and since fear represents a key human emotion, Behavioral Economics can be useful in minimizing the impact of this health and economic crisis. Even with the necessary information, changing certain habits is very difficult. However, the public sector and government institutions must try to change wrong behaviors. These behaviors must be effective and efficient, and require institutional and population-wide support. Behavioral Economy interventions that lead to better hygiene and prevention practices, in combination with what we know about the epidemiology of infectious diseases and the lessons we learn from the COVID-19 pandemic, will be part of the tools needed to seek solutions to curb the pandemic. We must normalize our psychological reactions in these days of uncertainty so that, understanding where they come from, we do not contribute to exacerbating the problem.

The correct transmission of information, trust in institutions that put public health before other interests, and awareness of our own biases and the importance of our individual responsibility are fundamental to getting out of this crisis. To help slow down the spread of the epidemic and to achieve a rapid recovery, it is essential to promote socially responsible behavior from Behavioral Economics, taking actions, such as those designed to promote, among other things, the use of masks or hand washing. Furthermore, given our tendency to imitate the behavior of others, solidarity-based behaviors must be implemented, such as collaborating in 
hygiene awareness campaigns or offering to care for the elderly or children. To this end, government institutions must promote awareness campaigns so that the population can put these effective measures into practice. Behavioral Economics is a key tool to face this health, social and economic crisis.

\section{References}

Battmann, W. \& Klumb, P. (1993). Behavioral economics and compliance with safety regulations. Safety Science, 16(1), 35-46.

Cárdenas, J. C., Maya, D. \& López, M. C. (2003). Métodos Experimentales y Participativos para el Análisis de la Acción Colectiva y la Cooperación en el Uso de Recursos Naturales por Parte de Comunidades Rurales. Cuadernos de Desarrollo Rural, número 50, PUJ Bogotá.

Duhigg, C. (2012). How companies learn your secrets. New York Times from http://www.nytimes.com/2012/02/19/magazine/shopping-habits.html)

Fatás, E. y. \& Roig, J. M. (2004). Una Introducción a La Metodología Experimental en Economía. Cuadernos de Economía, Número, 27, 7-36.

Fogg, B. (2009). A behavior model for persuasive design. In Proceedings of the 4th international Conference on Persuasive Technology, page 40. ACM.

Haushofer, J. y. \& Metcalf, J. (2020). Combining behavioral economics and infectious disease epidemiology to mitigate the COVID-19 outbreak.

Heshmat, S. (2011). Eating Behavior and Obesity: Behavioral Economics Strategies for Health Professionals. New York: Springer Publishing Company

Kahneman, D. (2013). Foreword. In E. Shafir (Ed.), The Behavioral Foundations of Public Policy (pp. vii-ix). New Jersey: Princeton University Press.

Kwok, Y. L. A., Gralton, J. \& McLaws, M. L. (2015). Face touching: A frequent habit that has implications for hand hygiene. American Journal of Infection Control, 43(2), 112-114.

Michie, S. \& Johnston, M. (2012). Theories and techniques of behavior change: Developing a cumulative science of behavior change. Health Psychology Review, 6(1), 1-6.

Samson, A. (Ed.) (2014). The Behavioral Economics Guide 2014 (with a foreword by George Loewenstein and Rory Sutherland), 1st Ed. Retrieved from http://www.behavioraleconomics.com.

Thaler, R. H. \& Sunstein, C. R. (2008). Nudge. Improving Decisions about Health, Wealth, and Happiness. New Haven: Yale University Press. 